\title{
Inspiring interfaces
}

\section{The arts and social sciences communities could enhance the commercial prospects of new materials.}

One of the greatest drivers of materials research today is its potential economic impact. And yet it is a sad fact that many materials science concepts developed in research laboratories will never become a commercial reality. Why is that? And what could be done to improve the commercial prospects of new materials? Answers to these questions may be found by venturing into the world of arts and consulting with social scientists. There are an increasing number of opportunities to explore these interfaces.

One such opportunity was the inaugural Inspiring Matter conference ${ }^{1}$ held at the Royal College of Art in London in April. Artists, product designers, architects, scientists and social scientists provided insights into their involvement with the development and application of new materials. For example, Mike Davies, an architect known for his work on the Millennium Dome and the Pompidou Centre, proposed his vision of the future of buildings with biomimetic skins that respond to the environment, can harvest energy, and can understand and respond to the needs and moods of their inhabitants. And Bradley Quinn, a trend forecaster, presented new clothing concepts inspired by self-assembly, light- and heat-responsive materials and aerosol technology (spray-on clothing; Fig. 1).

Although some of these ideas might seem far-fetched, they reveal how, unconstrained by scientific trends or perceived limitations, potential new applications and commercial opportunities could be opened up by artistic and scientifically creative minds working together. Not only that, but art itself could benefit from artists increasing their knowledge of new materials and processes, as Nature Materials has explored previously ${ }^{2}$.

The emotional response to different materials and their properties could also affect the economic success of a new technology. Sarah Wilkes, an anthropologist working for the UK Institute of Materials, Minerals and Mining, is studying systems of thought and considerations that inform materials scientists, manufacturers and designers when they make ethical judgements about materials. She uses interactive displays to probe the preconceptions that different communities may hold about the sustainability of a variety of materials, from leather to steel to silicone.

Her initial (unpublished) findings have suggested a generosity towards materials thought of as 'natural', irrespective of their

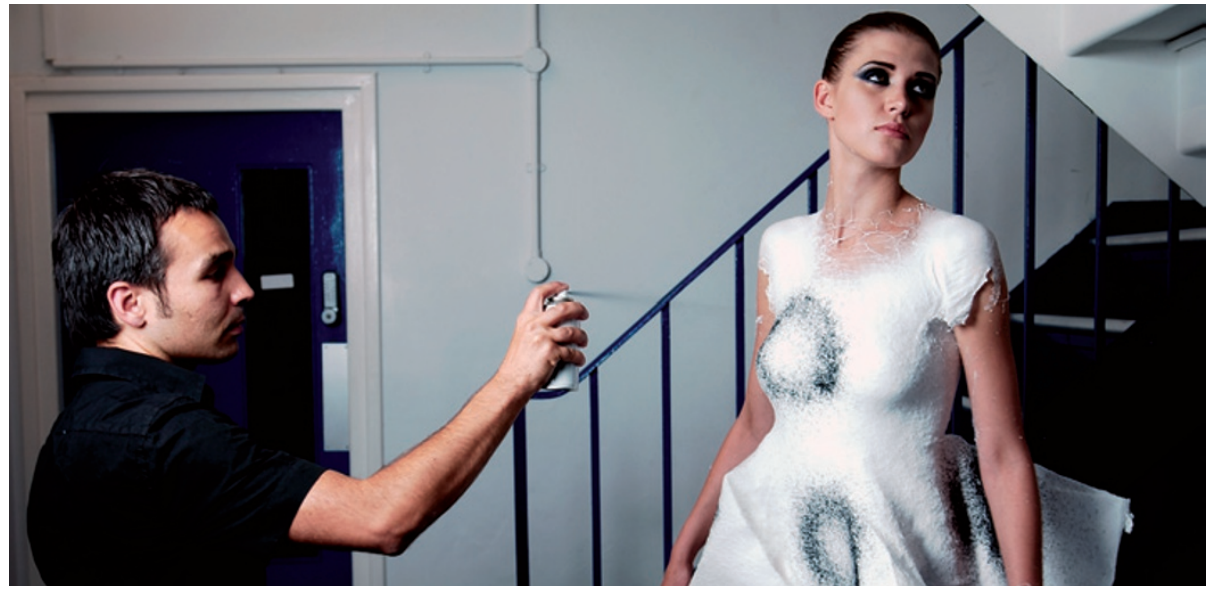

Figure 1 | Design and materials science meet. Dresses from aerosols by Fabrican (www.fabricanltd.com). Image by Gene Kiegel.

environmental impact. For example, leather manufacture has been criticized for the amount of organic and heavy metal waste it leaves behind, but received quite a favourable sustainability 'rating' from the materials and manufacturing community. She is interested to find out whether a similar response is observed from the design community. Newer, unfamiliar materials in the exhibition, on the other hand, such as medium-density fibreboard (MDF) and self-cleaning glass, received a generally unfavourable reception. This observation feeds into the general thesis that familiarity and longevity of use allows people to characterize materials with more certainty, and also increases their perceived sustainability. She is increasingly of the view that when designers, architects or engineers (materials users) are faced with a wide range of materials to choose from, the perceived sustainability of a material can have an impact on its commercial success.

A product's success could also be due to the sensory experience of the user. For example, weight is often associated with quality: think wine bottles and glasses, cutlery and furniture. Lighter structures may therefore seem cheap even if they are not ultra-lightweight titanium cutlery was a flop with passengers on Concorde some years ago. This issue has been explored in a recent publication entitled Rightweight ${ }^{3}$. The book discusses how this perception might change in future as less packaging could be associated with a superior product or brand following a sustainability agenda.
An increasing number of universities are receiving funding to explore the potential of social science and artistic creativity for materials science and technology. For example, the Umea Institute of Design in Sweden offers staff and students the chance to gain a deeper knowledge of materials science in their 'Prototyping the Future' project. And the University of Northumbria in the United Kingdom has established P3i, a new research studio and laboratory allowing designers and materials technologists to work together in a bid to enhance research and commercial output.

Historically the creative arts and the creation of new materials were closely aligned. But when materials development moved from a craft to a science these communities diverged, as has been discussed previously ${ }^{4}$. In the present day, these are tricky interfaces to work in. Designers and social scientists do not have many opportunities to develop their scientific understanding to aid interactions with scientists. There are also language barriers and a need for scientists to be patient and open-minded. But those willing to overcome these hurdles will find themselves at a new frontier of collaboration, creativity and, with luck, commercial opportunity.

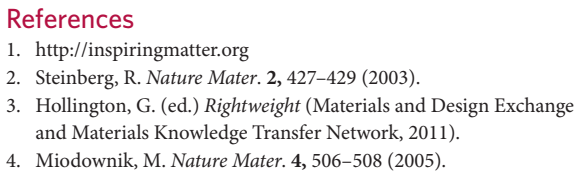

